\title{
The effect of low levels of stimulus intensity upon the orienting response
}

ANITA LEAVY AND JAMES H. GEER 1 UNIVERSITY OF PENNSYLVANIA

Sokolov's prediction of an inverse relationship between Orienting Response (OR) strength and low levels of stimulus intensity was tested using $48 \mathrm{Ss}$ and four stimulus intensity conditions. GSRs to a series of tones, $20,30,40$, or $50 \mathrm{~dB}$ in intensity, was employed as the measure of the OR. When spontaneous GSR frequency was held constant, $O R$ resistance to habituation was found to be a direct function of stimulus intensity, contrary to Sokolov's prediction.

In his book Perception and the Conditioned Reflex (1963), Sokolov reports that for low stimulus intensity levels, the strength of the orienting response (OR) is inversely related to stimulus intensity. In support of this statement, he presents the combined data obtained from 15 subjects, each of whom had been exposed to repeated presentations of a $1000 \mathrm{cps}$ tone at intensities ranging from 20 to $90 \mathrm{~dB}$ above zero. The Ss' galvanic skin responses (GSRs) to tones of a given intensity were allowed to habituate before tone presentations at the next intensity level were begun. The sum of the amplitudes of the GSRs to stlmull at each intensity level was taken as the measure of the strength of the OR for that level. The resulting U-shaped curve shows OR strength to be directly related to stimulus intensity levels above $50 \mathrm{~dB}$, but inversely related to intensity levels below $50 \mathrm{~dB}$. No tests of statistical significance accompany this finding, such tests seldom being employed in Soviet research.

While studies in this country have generally reported a direct relationship between $O R$ strength and stimulus intensity (Uno \& Grings, 1965; Zeaman \& Wegner, 1957), none has been specifically designed to test Sokolov's prediction with respect to the relationship between low intensity stimuli and the OR. Uno \& Grings (1965) found the magnitude of the OR to be a direct function of stimulus intensity, but used only stimulus intensitles of $60 \mathrm{~dB}$ and greater. Zeaman \& Wegner (1957) obtained similar results using auditory stimuli of subthreshold intensity, threshold intensity, and 27 $\mathrm{dB}$ above threshold (roughly $40 \mathrm{~dB}$ above zero for Ss with normal hearing). Since only one of these intensity levels falls within the range of low intensity stimuli employed by Sokolov, the latter's finding is not adequately tested by this study. The present experiment was designed for the purpose of evaluating Sokolov's finding using stimulus intensity levels of $50 \mathrm{~dB}$ and below, and employing standard techniques of data analysis.

Method

Ss were 24 male and 24 female undergraduates enrolled in an introductory psychology course. Ss were seated in an armchair in a sound-deadened chamber and were fitted with a set of earphones through which the stimuli were delivered. Zinc/zinc-sulfate electrodes were attached to S's right palm and wrist for the purpose of recording GSRs. A Beckman Model RB dynograph was the recording instrument.

After being checked to assure normal hearing, each $S$ was assigned to one of the following stimulus intensith conditions: $20,30,40$, and $50 \mathrm{~dB}$ above zero. $S$ was instructed that he would receive a number of tones and was told to listen quietly and to refrain from unnecessary movement. Following a 5-min rest period to permit stabllization of basal resistance level, $S$ listened to 16 presentations of a $1000 \mathrm{cps}$ tone of the appropriate intensity level. Presentations lasted $2 \mathrm{sec}$, and the average interstimulus interval was $100 \mathrm{sec}$. Resulis and Discussion

In analyzing the data, GSR amplitude scores were first obtained by taking the log of the change in skin conductance. Two measures were then employed as indices of OR strength: (1) the sum of the amplitudes of the GSRs to the 16 tone presentations (OR amplitude) and (2) the number of trials on which GSRs were elicited by the tone (OR resistance to habituation).

Initial analyses of variance showed no significant relationship between either measure of OR strength and stimulus intensity. Rather, the great intersubject variability with respect to OR strength appeared to be masking possible group differences. Previous research had pointed to reliable differences among individuals with respect to autonomic reactivity in general (Lacey \& Lacey, 1958) and with respect to the frequency of occurrence of spontaneous GSRs (SPGSRs) in particular (Kimmel, 1964). Furthermore, high correlations had been reported betwoen an individual's SPGSR frequency and his OR strength (Geer, 1966; Johnson, 1963; Stern et al, 1961). In view of our own finding in the present study of significant correlations between SPGSR frequency and OR amplitude $(r=.42$, $p<.002)$ and between SPGSR frequency and OR resistance to habituation $(r=.51, p<.001)$, an attempt was made to control for individual differences in GSR reactivity by holding SPGSR frequency constant. However, since complete records of the Si' SPGSR frequencies prior to the onset of the first stimulus were not avallable, it was impossible to control for the effects of the stimulus intensity conditions upon SPGSRs. In interpreting the following results, therefore, the reader should not overlook the possibllity of a nonindependent relationship between these two variables. 


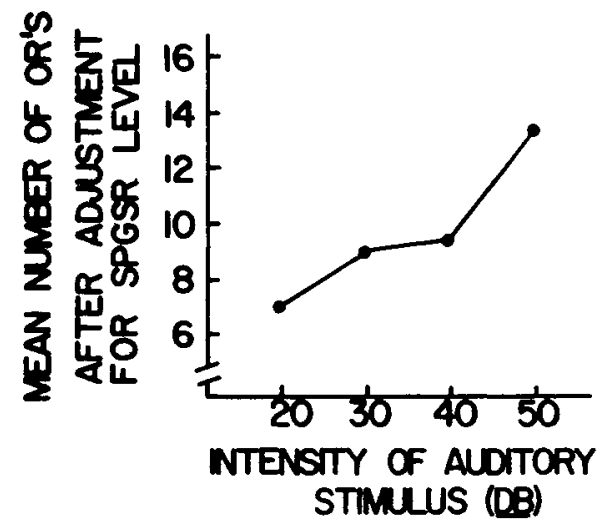

Fig. 1. Relationship between stimulus intensity and $O R$ resistance to habituation.

Using SPGSR frequency over the 16 trials as the covariant, a covariance analysis showed OR resistance to habituation to be a direct function of stimulus intensity $(p<.01)$. A similar, but nonsignificant relationship was found between or amplitude and stimulus intensity.

The study falled to replicate Sokolov's finding that OR amplitude is inversely related to stimulus intensity for weak stimull. Instead, resistance of the $O R$ to habltuation appears to be a direct function of stimulus intensity if one controls for individual differences in
ANS activity as indexed by SPGSRs. This result is more consistent with the usual finding of a direct relationship between stimulus intensfty and response strength.

\section{References}

GEER, J. H. Effect of interstimulus intervals and rest-period length upon habituation of the orienting response. J. exp. Psychol, 1966, 72, 617-619.

JOHNSON, L. C. Some attributes of spontaneous autonomic activity. J. comp. physiol Psychol, 1963, 56, 415-422.

KIMMEL, ELLEN. Individual differences in activation. Paper delivered at the meeting of the Southeast Psychol. Assoc., April, 1964.

LACEY, J. I., \& LACEY, B. C. The relationship of resting autonomic activity to motor impulsivity. In H. C. Solomon, S. Cobb, \& W. Penfield (Eds.), The brain and human behavtor. Baltimore: Williams \& Wilkins, 1958.

SOKLOV, E. N. Perception and the conditioned reflex. New York: Pergamon Press, 1963.

STERN, J., STEWARD, M. A., \& WINOKUR, G. An investigation of some relationships between various measures of galvanic skin response. J. Psychosom. Res, 1961, 5, 215-223.

UNO, T., \& GRINGS, W. W. Autonomic components of orienting behavior. Psychophysiol, 1965, 1, 311-321.

ZEAMAN, D., \& WEGNER, NORMA. Cardiac reflex to tones of threshold intensity. J. Speech hear. Disord, 1957, 21, 71-75.

\section{Note:}

1. Now at the State University of New York at Stonybrook.

2. The present study was supported by United States Public Health Service Grant MH-12301-01. The investigators are grateful to Janice Mazer and Jeanne Salis for their help in collecting the data. 